\title{
Cardiopulmonary responses to exercise in patients with hypertrophic cardiomyopathy
}

\author{
S Jones, P M Elliott, S Sharma, W J McKenna, B J Whipp
}

\begin{abstract}
Objective-To examine the submaximal and maximal indices of the exercise response of patients with hypertrophic cardiomyopathy.

Design and setting-Prospective examination of cardiopulmonary responses to ramp exercise test of a consecutive group of patients with hypertrophic cardiomyopathy attending a cardiomyopathy outpatient clinic.
\end{abstract}

Methods-50 patients aged 12 to 76 years (mean (SD) 35 (14)) with diagnosis of hypertrophic cardiomyopathy performed incremental cycle ergometry; 22 sedentary volunteers (seven female, 15 male) aged 14 to 58 years (mean (SD) 31 (12)) served as controls. Respiratory gas was continuously sampled from the mouthpiece, and its concentration profile phase aligned to the respired air flow signals. Following analogue to digital conversion, gas exchange variables were computed breath by breath and the data were averaged every 30 seconds for graphic display. A 12 lead ECG was monitored continuously and recorded every three minutes during the exercise.

Results-Both the peak oxygen uptake attained on the test ( $\dot{V}_{2}$ peak) and anaerobic threshold were reduced in patients with hypertrophic cardiomyopathy compared with the control group $(p<0.0001)$. In 29 patients $(59 \%)$ the $\dot{V} o_{2}$ peak was less than $60 \%$ and only two patients achieved a peak above $80 \%$ of their predicted values. The anaerobic threshold was below $60 \%$ of the predicted value in 31 patients and above $80 \%$ in only three patients. The slope of oxygen uptake/ work rate relation $\left(\Delta \dot{\mathbf{V}} o_{2} I \Delta W R\right)$ was decreased in 16 patients $(32 \%)$. The maximum oxygen pulse $\left(\dot{\mathrm{V}}_{2} / \mathrm{HR}\right)$ was reduced as a percentage of the predicted value, and became flat at high work rates in 32 patients. There was a significant correlation between anaerobic threshold and $\dot{V}_{\mathrm{O}_{2}}$ peak $(\mathrm{p}<\mathbf{0 . 0 0 0 1})$, work efficiency $(\mathrm{p}<0.0001)$, and maximum oxygen pulse $(p<0.0001)$. The slope of change in ventilation against change in carbon dioxide output $\left(\Delta \dot{\mathbf{V}} E / \Delta \dot{\mathbf{V}} \mathrm{CO}_{2}\right)$ for the subanaerobic threshold range was increased in 36 patients (72\%) and was inversely correlated with anaerobic threshold $(\mathrm{p}<0.0002)$.

Conclusions-There were severe abnormalities in maximal and submaximal indices of pulmonary gas exchange in a cohort of hypertrophic cardiomyopathy patients attending a referral cardiovascular clinic. The pattern of the abnormalities suggests that a reduced stroke volume response, ventilation/perfusion mismatch, and abnormal peripheral oxygen utilisation are the possible mechanisms of exercise intolerance.

(Heart 1998;80:60-67)

Keywords: exercise tolerance; work efficiency; oxygen pulse; hypertrophic cardiomyopathy

The pattern of ventilatory and pulmonary gas exchange response to an appropriate exercise test can be used to gain information on both the cause and degree of exercise intolerance. ${ }^{12}$ Breath by breath computation and display of a selected cluster of variables have been widely used to discriminate between respiratory and circulatory causes of exercise intolerance. ${ }^{13}$ The most commonly used index of functional limitation in patients with cardiovascular disorders is the peak oxygen uptake ( $\dot{\mathrm{V}}_{2}$ peak). This is usually below the predicted value compared with age, sex, and height matched normal controls, owing to impaired oxygen delivery to the contracting muscle. In addition, patients typically become "detrained" as a result of decreased levels of activity and the $\dot{\mathrm{V}}_{2}$ peak is further reduced. There are currently no valid means of estimating what proportion of the reduced $\dot{\mathrm{V}}_{2}$ peak can be attributed to the cardiovascular disorder itself and what to detraining. Furthermore, symptoms such as pain may prevent patients from making a maximum effort, and apprehension and fear of "bringing on an attack" can lead to exercise cessation even before the onset of symptoms. The $\dot{\mathrm{V}}_{2}$ peak may not therefore be a valid index of functional capacity in such patients

While various studies of cardiopulmonary response to exercise have shown a reduction in peak oxygen uptake in patients with hypertrophic cardiomyopathy, little is known about the behaviour of other indices in the gas exchange profiles in these patients. The aim of this study was therefore to characterise the profiles of a range of cardiopulmonary responses during ramp incremental exercise and to establish their relation to indices of exercise tolerance and symptoms in a population of patients with hypertrophic cardiomyopathy.

\section{Methods}

We studied 50 consecutive patients with hypertrophic cardiomyopathy who were attending the cardiomyopathy clinic at St George's Hospital (table 1). Patients who had undergone
Accepted for publication 23 February 1998 
Table l Patient characteristics

\begin{tabular}{|c|c|c|c|c|c|c|}
\hline No & Age (years) & Sex & $\begin{array}{l}\text { Weight } \\
(\mathrm{kg})\end{array}$ & $\begin{array}{l}\text { Height } \\
(\mathrm{cm})\end{array}$ & $\begin{array}{l}\text { Maximum wall } \\
\text { thickness (mm) }\end{array}$ & $\begin{array}{l}\text { Gradient } \\
(\mathrm{mm} \mathrm{Hg})\end{array}$ \\
\hline 1 & 17 & M & 81 & 183 & 21 & 5.76 \\
\hline 2 & 30 & M & 83 & 180 & 14 & 5.76 \\
\hline 3 & 36 & $\mathrm{~F}$ & 66 & 162 & 20 & 92.16 \\
\hline 4 & 62 & $\mathrm{~F}$ & 51 & 164 & 11 & 5.76 \\
\hline 5 & 34 & $\mathrm{~F}$ & 45 & 153 & 24 & 57.76 \\
\hline 6 & 35 & M & 81 & 180 & 19 & 5.76 \\
\hline 7 & 31 & $\mathrm{~F}$ & 44 & 157 & 21 & 70.6 \\
\hline 8 & 35 & $\mathrm{~F}$ & 56 & 146 & 18 & 96 \\
\hline 9 & 44 & M & 83 & 183 & 21 & 4 \\
\hline 10 & 12 & M & 30 & 149 & 13 & 6.76 \\
\hline 11 & 19 & $\mathrm{~F}$ & 60 & 160 & 26 & 70.6 \\
\hline 12 & 18 & M & 75 & 186 & 19 & 10.24 \\
\hline 13 & 14 & M & 50 & 165 & 24 & 8.84 \\
\hline 14 & 34 & M & 84 & 180 & 29 & 12.96 \\
\hline 15 & 31 & $\mathrm{~F}$ & 82 & 175 & 23 & 7.84 \\
\hline 16 & 49 & M & 77 & 182 & 14 & 4 \\
\hline 17 & 26 & $M$ & 80 & 176 & 23 & 3.24 \\
\hline 18 & 49 & M & 96 & 184 & 15 & 36 \\
\hline 19 & 18 & M & 88 & 170 & 12 & 16 \\
\hline 20 & 18 & $\mathrm{~F}$ & 46 & 162 & 19 & 21.16 \\
\hline 21 & 23 & $\mathrm{~F}$ & 50 & 165 & 30 & 10.24 \\
\hline 22 & 21 & $\mathrm{~F}$ & 54 & 163 & 25 & 38.44 \\
\hline 23 & 48 & $\mathrm{~F}$ & 70 & 157 & 17 & 96 \\
\hline 24 & 23 & M & 84 & 186 & 21 & 4.84 \\
\hline 25 & 14 & M & 61 & 186 & 16 & 6.24 \\
\hline 26 & 50 & M & 65 & 174 & 38 & 5.76 \\
\hline 27 & 62 & $\mathrm{~F}$ & 111 & 165 & 11 & 14.44 \\
\hline 28 & 28 & $\mathrm{~F}$ & 55 & 171 & 21 & 6.76 \\
\hline 29 & 37 & M & 104 & 181 & 25 & 5.76 \\
\hline 30 & 20 & M & 72 & 180 & 28 & 7.84 \\
\hline 31 & 42 & M & 84 & 180 & 22 & 16 \\
\hline 32 & 22 & M & 54 & 173 & 8 & 16 \\
\hline 33 & 33 & M & 89 & 173 & 19 & 4.84 \\
\hline 34 & 46 & $M$ & 90 & 173 & 10 & 31.36 \\
\hline 35 & 49 & M & 99. & 185.5 & 18 & 10.24 \\
\hline 36 & 35 & M & 86 & 190 & 25 & 7.87 \\
\hline 37 & 33 & $M$ & 84 & 166 & 15 & 11.56 \\
\hline 38 & 42 & M & 79 & 177 & 12 & 4 \\
\hline 39 & 60 & $\mathrm{~F}$ & 76 & 164 & 12 & 5.76 \\
\hline 40 & 24 & M & 69 & 182 & 10 & 5.76 \\
\hline 41 & 45 & M & 100 & 178 & 22 & 100 \\
\hline 42 & 39 & M & 74 & 183 & 9 & 5.76 \\
\hline 43 & 59 & $\mathrm{~F}$ & 45 & 155 & 18 & 64 \\
\hline 44 & 48 & M & 86 & 170 & 16 & 29.2 \\
\hline 45 & 28 & M & 95 & 175 & 15 & 16 \\
\hline 46 & 35 & $M$ & 84 & 165 & 20 & 57.76 \\
\hline 47 & 40 & M & 75 & 178 & 12 & 6.76 \\
\hline 48 & 34 & $\mathrm{~F}$ & 111 & 162 & 14 & 5.75 \\
\hline 49 & 60 & M & 73 & 155 & 17 & 6.9 \\
\hline 50 & 20 & $M$ & 67 & 177 & 18 & 11.6 \\
\hline
\end{tabular}

^Pressure gradient across the left ventricular ouflow (mean $23(28) \mathrm{mm} \mathrm{Hg}$ ).

myotomy-myectomy, those with a pacemaker in situ, those with abnormal blood pressure response to exercise, and those who had established atrial fibrillation were excluded, to minimise the number of complicating features. The study group included 15 females and 35 males, aged 12 to 62 years, mean (SD) 35 (14) years. The diagnosis of hypertrophic cardiomyopathy was based on conventional WHO criteria, ${ }^{4}$ that is, unexplained left ventricular hypertrophy in excess of that predicted for age, sex, and body surface area. Nine patients, within this cohort did not fulfil the WHO criteria for hypertrophic cardiomyopathy, but these were either obligate or proved gene carriers. ${ }^{5}$

The left ventricular dimensions were: maximum wall thickness, 0.8 to $3.8 \mathrm{~cm}$, mean (SD) 19 (6) $\mathrm{cm}$; left ventricular end diastolic dimension, 3 to $5.4 \mathrm{~cm}$, mean (SD) $4.2(0.6) \mathrm{cm}$; and left ventricular end systolic dimension, 1.2 to $3.5 \mathrm{~cm}$, mean (SD) $2.4(0.6) \mathrm{cm}$. The left atrial dimension was 2.9 to $6.8 \mathrm{~cm}$, mean (SD) 4.1 $(0.8) \mathrm{cm}$. Eleven patients had a left ventricular outflow gradient greater than $30 \mathrm{~mm} \mathrm{Hg}$. All the patients had an abnormal resting ECG and nine were asymptomatic. Of those with symptoms, 28 had chest pain; this was exertional in
15, atypical (not associated with exertion) in four, atypical and exertional in nine. Thirteen of the patients had a history of presyncope and five had syncope. Twenty four patients had New York Heart Association (NYHA) grade II dyspnoea and five had NYHA grade III dyspnoea. Forty two of the patients were on drugs: seven on amiodarone, 16 on calcium channel blockers, six on disopyramide, and 13 on $\beta$ blockers. Patients were requested not to take these drugs for 48 hours before their exercise tests. With the exception of amiodarone, the half life for these drugs is approximately eight hours, with a time constant of 12 hours. As four time constants are required for the clearance of these drugs, we chose 48 hours as an appropriate time to minimise both the effects of the drugs and the time during which the patients were off treatment. The half life of amiodarone is up to 100 days. We therefore thought it prudent to allow patients to continue with this drug.

Twenty two sedentary volunteers (seven female, 15 male) aged 14 to 58 years, mean (SD) 31 (12) years, served as controls. The control group consisted of individuals who had no medical history of cardiovascular or other systemic disorders. None was involved in heavy exercise or athletic training. Three of the volunteers exercised regularly (two jogged three times a week to keep fit and one played squash occasionally), while five of the patients also exercised to keep fit. The control group was age and sex matched to the patients. Six of the volunteers and 22 of the patients had had previous exercise tests. The formula of Wasserman et al was used to calculate the predicted $\dot{\mathrm{V}}_{\mathrm{O}_{2}}$ peak for both the control and the patient groups. ${ }^{1}$

The exercise tests were performed in the morning in all cases, in an air conditioned exercise laboratory (average temperature of $21^{\circ} \mathrm{C}$ ) with full resuscitation facilities and two investigators present at all times. All subjects were told what was expected of them and were appraised of the signals to be used to communicate with those in attendance during the test. All subjects were given the opportunity to become familiar with the cycle ergometer. The saddle height was individually adjusted and the subjects' feet were secured to the pedals with straps. The work rate for the incremental exercise ranged from 5 to $15 \mathrm{~W} / \mathrm{min}$ and was based on patients' account of daily physical activity, age, sex, and medical history. The aim was to achieve an exercise time of 10 minutes $^{1}$ by selecting the appropriate exercise ramp rate for each patient. Subjects rode to the limit of volitional tolerance.

A previously calibrated ${ }^{6}$ and electronically braked cycle ergometer (Medgraphics Cardio 2; Medical Graphics Corporation, St Paul, Minnesota, USA) was used to exercise the subjects in an upright position. This system provides an actual "zero" load with unloaded cycling - that is, a "motor assist" overcomes the mechanical resistance normally present at zero load cycling (often 20 to $30 \mathrm{~W}$ or more). The subjects began the incremental ramp ${ }^{7}$ after three minutes of unloaded pedalling. They 


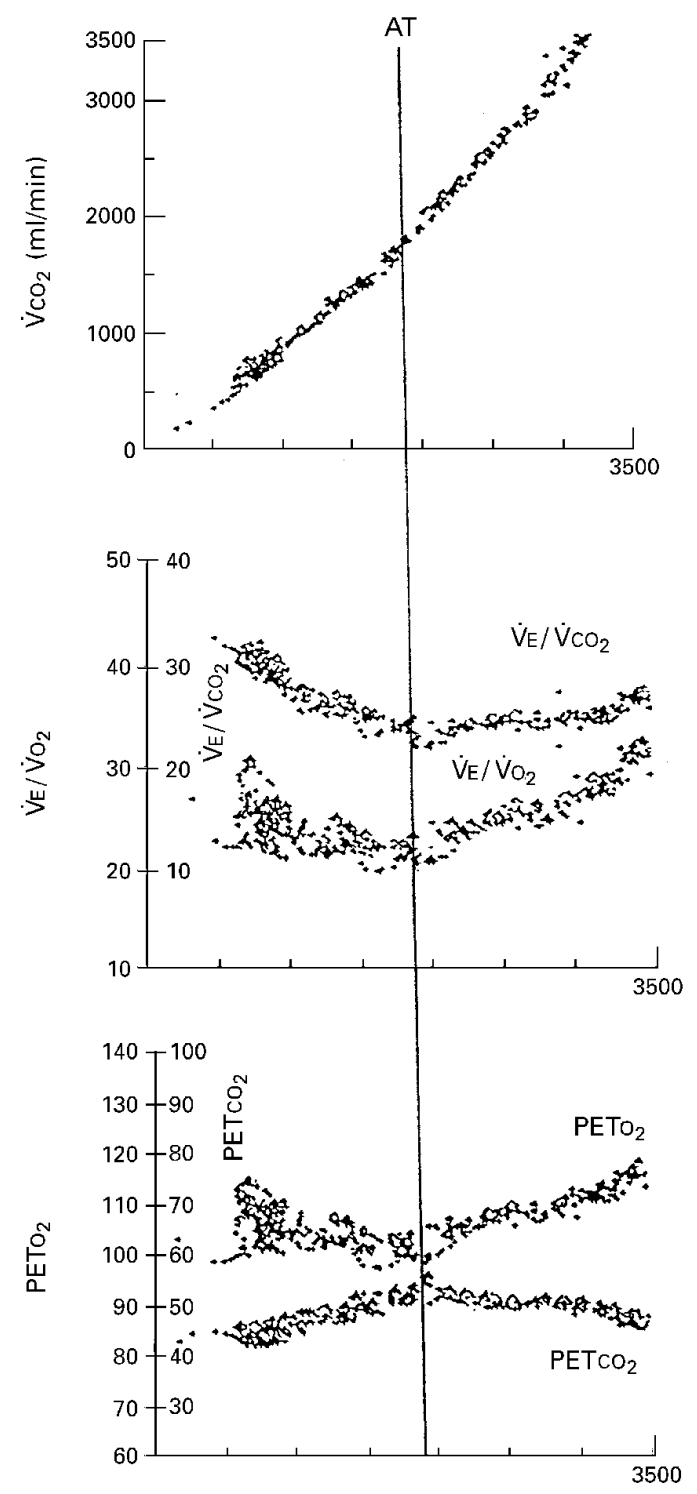

$\dot{\mathrm{V}}_{2}(\mathrm{ml} / \mathrm{min})$
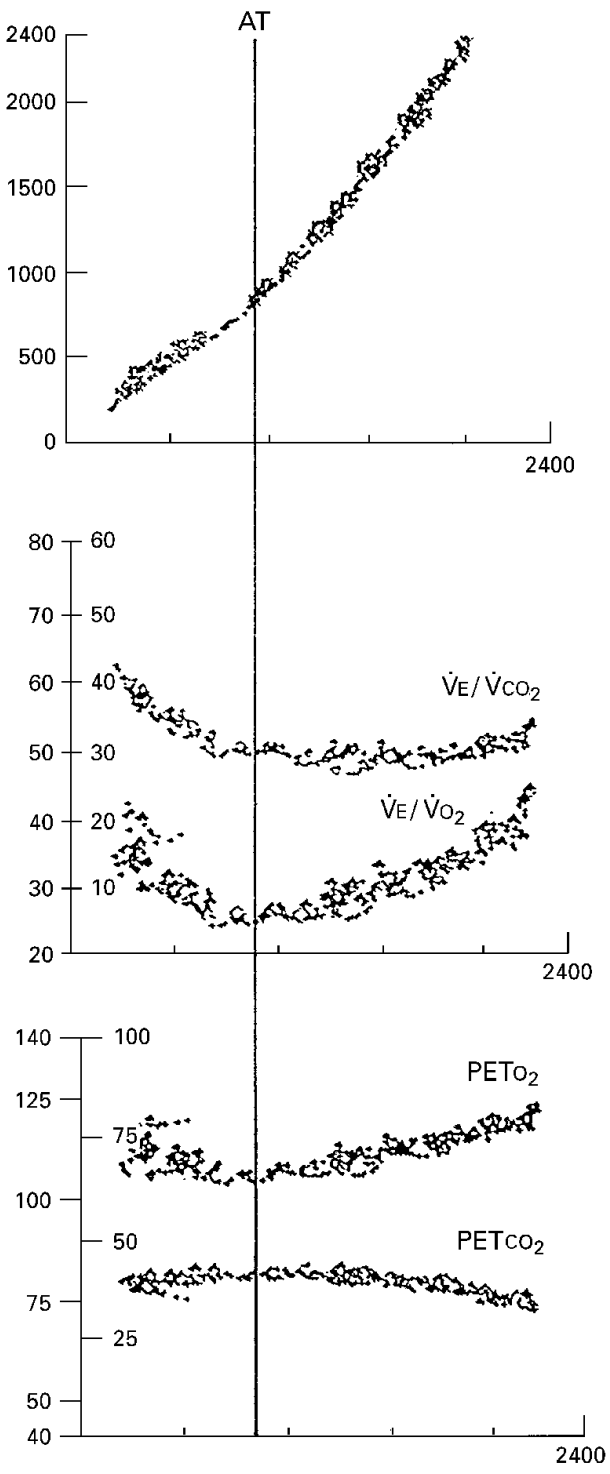

$\dot{\mathrm{V}}_{2}(\mathrm{ml} / \mathrm{min})$

Figure 1 Profile of response of $\dot{V}_{\mathrm{CO}_{2}}$ (uppermost panels), ventilatory equivalent for $\dot{V}_{2}$ and $\dot{V}_{\mathrm{CO}_{2}}$ (middle panels), and end tidal $\mathrm{PO}_{2}$ and end tidal $\mathrm{PCO}_{2}$ (lower panels) as a function of oxygen uptake during an incremental test to the limit of tolerance in a male control (left panels) and a patient with hypertrophic cardiomyopathy (right panels). Note the reduced anaerobic threshold in the patient.

breathed room air through a disposable, low resistance (approximately $1.2 \mathrm{~cm} / 1 / \mathrm{min}$ at 12 $1 / \mathrm{min}$ ), low dead space $(39 \mathrm{ml})$ flow meter. ${ }^{8}$ The flow meter was calibrated with a three litre syringe, using a range of flows. Respiratory gas was sampled continuously from the mouthpiece and analysed using a zirconia cell for oxygen and an infrared sensor for carbon dioxide. These signals underwent analogue to digital conversion for breath by breath calculation of $\dot{\mathrm{V}}_{2}$ and $\dot{\mathrm{V}}_{\mathrm{CO}_{2}}$, using algorithms based on the procedure of Beaver et al. ${ }^{9}$ Signals from a 12 lead ECG were displayed continuously for observation, and recorded at regular intervals during the exercise and in the recovery phase. Blood pressure was determined by auscultation at one minute intervals during the test and recovery phase.

The anaerobic threshold was determined from the plot of $\dot{\mathrm{V}}_{2}$ against $\dot{\mathrm{VO}}_{2}$, as described by Beaver $e t a l^{9}$ and Sue $e t a l,{ }^{10}$ where the slope of this linear relation increases owing to a rise in $\dot{\mathrm{V}} \mathrm{CO}_{2}$ (V slope) (fig 1). Further confirmation of the anaerobic threshold was provided from $\dot{\mathrm{V}} / \dot{\mathrm{V}}_{\mathrm{CO}_{2}}, \dot{\mathrm{V}} \mathrm{E} / \dot{\mathrm{V}}_{2}$, end tidal $\mathrm{PCO}_{2}$, and end tidal $\mathrm{PO}_{2}$ relations, as described by Whipp et al, ${ }^{11} \dot{\mathrm{V}} \mathrm{E}$ being ventilation (expired volume per minute). The linear region of the plot (fig 1) of $\dot{\mathrm{V}}_{2}$ against work rate $\left(\Delta \dot{\mathrm{V}}_{2} / \Delta \mathrm{WR}\right)$ has been shown to be a major determinant of the subject's aerobic efficiency or more properly its inverse proportionality.

The heart rate response as a function of work rate was examined for its maximum value and its slope. The oxygen pulse $\left(\dot{\mathrm{V}}_{2} /\right.$ heart rate) was also determined; this is numerically equivalent to the product of the stroke volume and the arteriovenous difference in oxygen content, that is: 


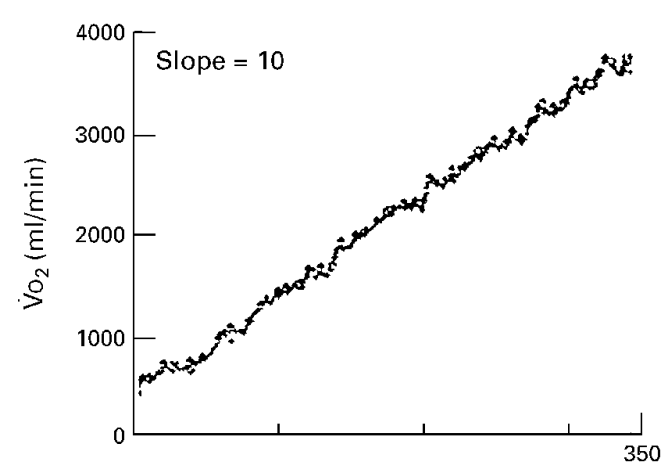

Watts

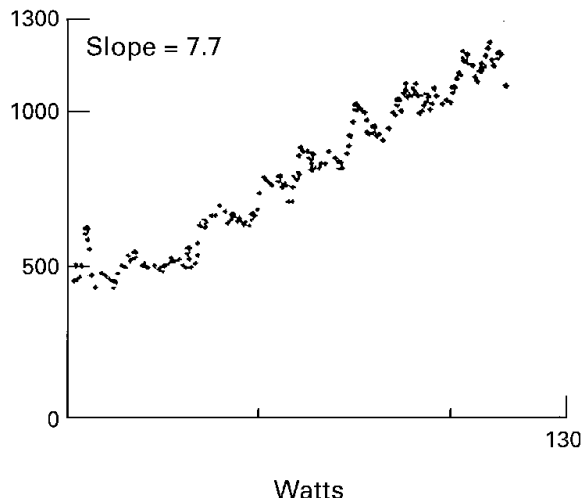

Watts

Figure 2 The profile of $\dot{V}_{\mathrm{O}_{2}}$ response, as a function of work rate, in incremental exercise test in a control subject (left panel) and a patient with hypertrophic cardiomyopathy (HCM) (right panel). Note the reduced slope of this relation in the patient with HCM.

$\dot{\mathrm{V}} \mathrm{O}_{2}=\mathrm{HR} \times \mathrm{SV} \times \mathrm{C}(\mathrm{a}-\dot{\mathrm{v}}) \mathrm{O}_{2}$ $\therefore \dot{\mathrm{V}} \mathrm{O}_{2} / \mathrm{HR}=\mathrm{SV} \times \mathrm{C}(\mathrm{a}-\dot{\mathrm{v}}) \mathrm{O}_{2}$

Where $\dot{\mathrm{VO}}_{2}$ is maximum oxygen uptake, $\mathrm{HR}$ is the heart rate, $\mathrm{SV}$ is the stroke volume, and $\mathrm{C}(\mathrm{a}-\mathrm{v}) \mathrm{O}_{2}$ is the arterial-mixed venous oxygen content difference.

"Flattening" of the oxygen pulse profile as a function of work rate has previously been shown in patients with cardiovascular disease. ${ }^{12}$ The "flatness" of the oxygen pulse was characterised in relation to the number of work rate increments over which the oxygen pulse was unchanged (expressed as percentage of maximum work rate). The range of the flatness of the oxygen pulse was calculated by identifying a region in the high work rate that was clearly flat and superimposing a line of best fit with zero slope through these data points. The point where the actual data points departed from the line of best fit was considered to be the work rate at which the oxygen pulse became flat.

The slope of $\dot{\mathrm{V}} \mathrm{E} / \dot{\mathrm{V}}_{\mathrm{CO}_{2}}$ was determined from the lower linear region of the plot of $\dot{V}_{E}$ as a function of $\dot{\mathrm{V}}_{\mathrm{CO}_{2}}$, that is, the subanaerobic threshold region.

The Pearson correlation analysis and $t$ test were used to test significance (assumed at $\mathrm{p}<0.05)$.

\section{Results}

Exercise testing was performed without complications or the development of sustained supraventricular or ventricular arrhythmia. The patients terminated exercise for a variety of reasons: dyspnoea in 13, chest pain in eight, leg pain in seven, light headedness in two, exhaustion in 14, and leg pain and exhaustion in six. The duration of exercise was 4.5 to 22 minutes (mean (SD) 10.4 (3)).

PEAK OXYGEN UPTAKE

The peak $\dot{\mathrm{V}}_{2}$ was significantly reduced in patients with hypertrophic cardiomyopathy (9.4 to $32 \mathrm{ml} / \mathrm{min} / \mathrm{kg}$, mean (SD) 20.94 (6.05)) compared with the controls (27.5 to 43.4 $\mathrm{ml} / \mathrm{min} / \mathrm{kg}$, mean (SD) $35.17 \quad(5.6)$ ) $(\mathrm{p}<0.0001)$. Twenty nine patients $(58 \%)$ had a $\dot{\mathrm{V}}_{2}$ peak less than $60 \%$ of the predicted value. Nineteen $(38 \%)$ achieved values between $60 \%$ and $80 \%$ of predicted. Only two patients $(4 \%)$ achieved a $\dot{\mathrm{V}}_{2}$ peak in excess of $80 \%$ the predicted value.

ANAEROBIC THRESHOLD

In the patients, the anaerobic threshold was 3.8 to $15.8 \mathrm{ml} / \mathrm{min} / \mathrm{kg}$ (mean (SD) 9.9 (2.71)), compared with 11.5 to $26 \mathrm{ml} / \mathrm{min} / \mathrm{kg}$ (mean (SD) $18.56(4.5))$ in the controls $(\mathrm{p}<0.0001)$. In 31 patients $(62 \%)$, the anaerobic threshold was below $60 \%$ of the predicted value. Sixteen patients $(32 \%)$ achieved values between $60 \%$ and $80 \%$ of their predicted value. Only three patients reached an anaerobic threshold in excess of $80 \%$ of the predicted value; two of these patients had also achieved a peak $\dot{\mathrm{V}}_{2}$ of more than $80 \%$ of the predicted value.

\section{OXYGEN UPTAKE/WORK RATE RELATION}

The linear region of the plot of oxygen uptake against work rate had a slope of 6 to 11 $\mathrm{ml} / \mathrm{min} / \mathrm{W}$ (mean (SD) 9.2 (1.3)), compared with 9.2 to $11(10.1(0.5))$ in the controls $(\mathrm{p}<0.0013)$. This slope was normal in 34 patients $(68 \%)$. The remaining 16 patients had an abnormally low slope for this relation (fig 2).

\section{OXYGEN PULSE}

The maximum oxygen pulse $\left(\dot{\mathrm{V}}_{2} / \mathrm{HR}\right)$ was reduced to 4 to $17 \mathrm{ml} /$ beat (mean (SD) 9.96 (3.11)), compared with 9 to $22 \mathrm{ml} /$ beat $(15.33$ (3.88)) in the controls $(\mathrm{p}<0.0002)$. In 32 patients $(64 \%)$, the $\dot{\mathrm{V}}_{2} / \mathrm{HR}$ relation did not continue to increase with the pattern expected in the control subjects but became constant or "flat" over higher work rates. This was associated with a more rapid rate of increase in heart rate, as shown in fig 3 . The extent of the flatness of the oxygen pulse ranged from $20 \%$ to $50 \%$ of the maximum work rate in 32 patients. The maximum heart rate response to exercise was, however, significantly greater in the controls, at 154 to 197 beats/min (mean (SD) 176 (11)) compared with 94 to 185 beats/min (156 (20)) in the controls $(\mathrm{p}=0.0003)$. In 14 patients $(28 \%)$ both the peak oxygen pulse and the peak heart rate response were reduced, although the pattern of oxygen pulse was normal. In four patients $(8 \%)$ who attained a normal value for the peak oxygen pulse, the peak heart rate response was less than $70 \%$ of the predicted value for their age and height. 


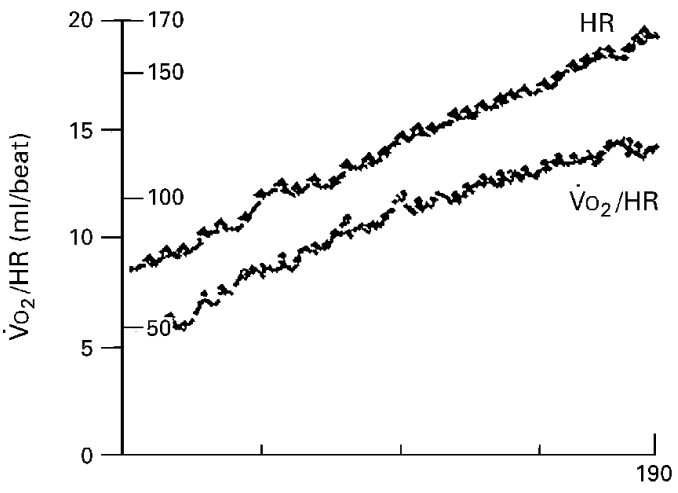

Watts

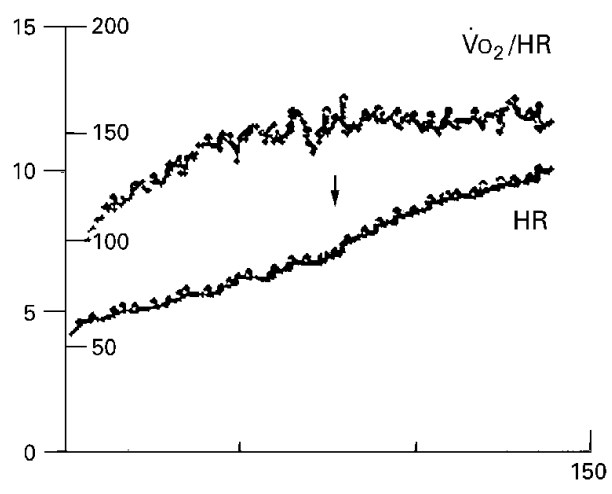

Watts

Figure 3 Profile of response of heart rate and oxygen pulse to progressively increasing work rate to limit of tolerance in a control subject (left panel) and in a patient with hypertrophic cardiomyopathy (HCM) (right panel). Note that the oxygen pulse continues to increase throughout the work rate in the control subject, whereas it reaches a plateau at some $60 \%$ of the maximum work rate in a patient with HCM. Note also the clearly discernible increase in the heart rate response at the work rate at which the oxygen pulse begins to plateau.

$\dot{\mathrm{V} E} / \dot{\mathrm{V} C \mathrm{O}_{2}}$

The $\dot{V} E$ response as a function of $\dot{\mathrm{V}} \mathrm{CO}_{2}$ in the subthreshold range, that is below anaerobic threshold, was increased in the patients with hypertrophic cardiomyopathy, at 17 to 50 (mean (SD) $30(7)$ ), compared with 17 to 27 $(22$ (3)) in the controls $(\mathrm{p}<0.0002)$ (fig 4$)$. Twenty six patients had values above 30 .

INTERRELATIONS AMONG GAS EXCHANGE INDICES The maximum left ventricular wall thickness was not related to any measures of exercise response (fig 5). Nor did any pretest symptoms correlate with the indices of the exercise profile. Patients with lowest anaerobic threshold tended to have the lowest peak $\dot{\mathrm{V}}_{2}$ $(r=0.83, \mathrm{p}<0.0001), \dot{\mathrm{V}}_{2} / \mathrm{WR} \quad(r=0.53$, $\mathrm{p}<0.0001)$, and $\dot{\mathrm{V}}_{2} / \mathrm{HR} \quad(r=0.85$, $\mathrm{p}<0.0001$ ) (fig 6). The slope of $\dot{\mathrm{V}} / \dot{\mathrm{V}}_{\mathrm{CO}_{2}}$, however, was an inverse function of the degree of impairment (fig 4) - that is, the subjects with the lowest anaerobic threshold or peak $\dot{\mathrm{V}}_{2}$ had the highest slope $(r=0.5, \mathrm{p}<0.0002)$, the relation being linear.

\section{INTERRELATION BETWEEN GAS EXCHANGE}

INDICES AND CLINICAL FEATURES

There was no association between maximum wall thickness and exercise limitation in this group of patients. When considered separately,

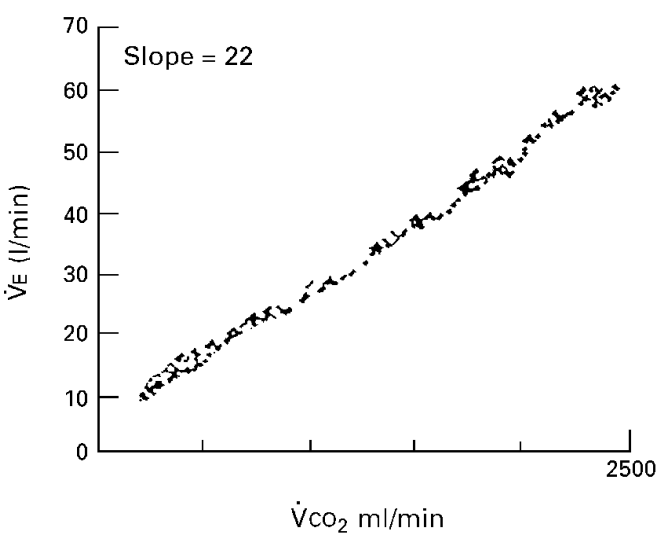

there was no significant difference between those with normal wall thickness and those whose left ventricular wall thickness exceeded $15 \mathrm{~mm}$. There was no significant difference in either the peak or the submaximal levels of exercise response between the patients with normal and the patients with increased left ventricular outflow gradient (gradient $>30$ $\mathrm{mm} \mathrm{Hg}$ ).

\section{Discussion}

Our study confirms that patients with hypertrophic cardiomyopathy have reduced peak oxygen uptake compared with controls. However, in isolation, the interpretation of peak exercise variables in patients with cardiovascular disease is difficult as these can be reduced by "detraining" and by symptoms that cause patients to stop exercise before reaching true maximum exercise capacity. For these reasons, submaximal exercise responses are likely to give a greater insight into the mechanisms of exercise limitation in patients with heart disease.

\section{OXYGEN PULSE}

Oxygen pulse $\left(\dot{\mathrm{V}}_{2} / \mathrm{HR}\right)$ is numerically equivalent to the product of stroke volume and the arteriovenous oxygen content difference. In normal individuals it usually increases in a

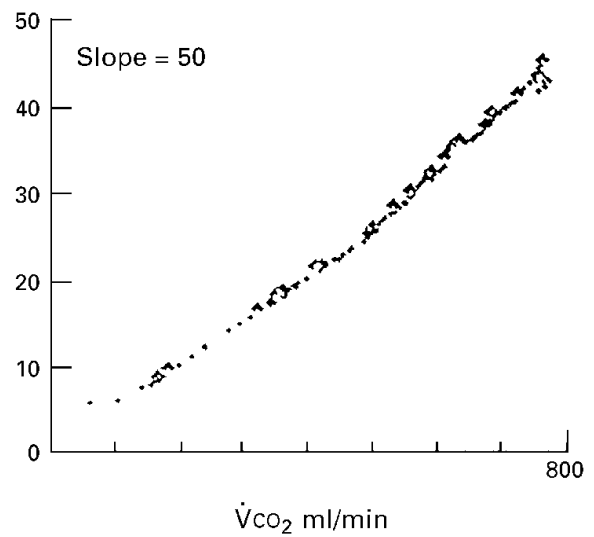

Figure 4 Profile of the ventilatory response as a function of $\dot{V}_{\mathrm{CO}_{2}}$ during an incremental exercise test to the limit of tolerance in a control subject (left panel) and a patient with hypertrophic cardiomyopathy (right panel). Note the high slope in the patient. 

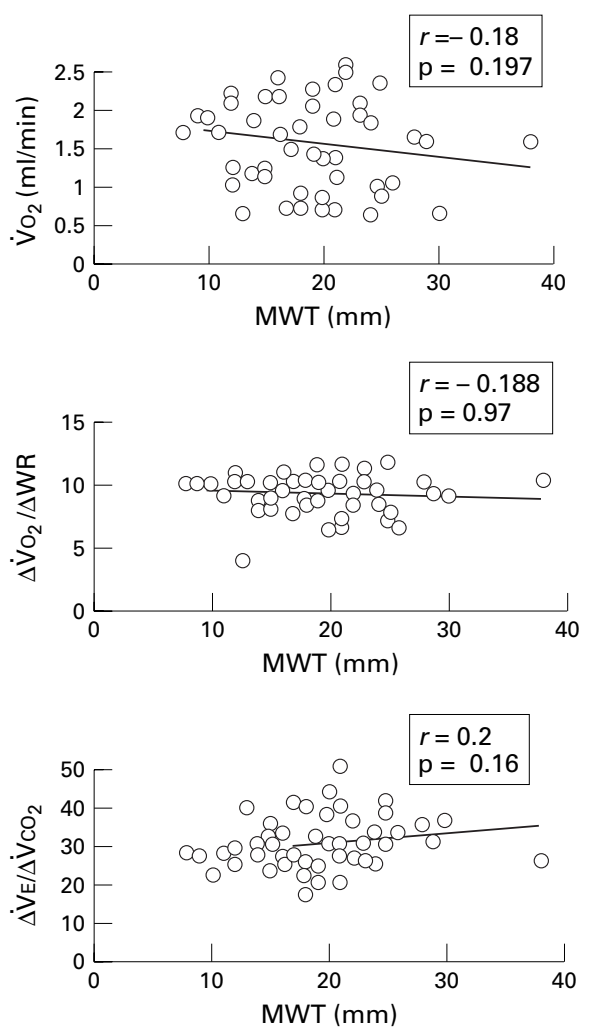

hyperbolic fashion ${ }^{13}$ up to maximum oxygen uptake. For the initial $40-50 \%$ of oxygen uptake this increase is brought about by the augmentation of stroke volume and the widening of the arteriovenous oxygen content difference, but at higher work rates stroke volume reaches a plateau $^{1415}$ or even falls. ${ }^{16}$ The continuing rise in oxygen pulse is then largely dependent on increases in arteriovenous oxygen difference. ${ }^{1617}$ In our study, the low maximum value of oxygen pulse is consistent with the failure to continue to increase stroke
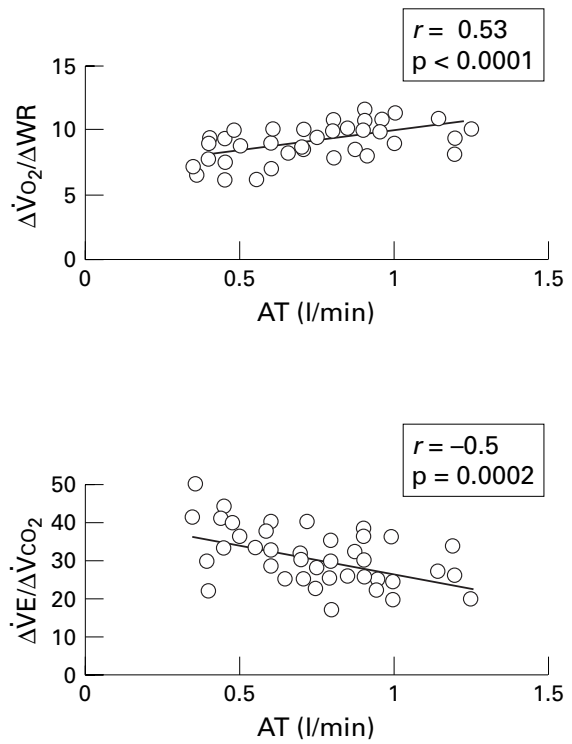
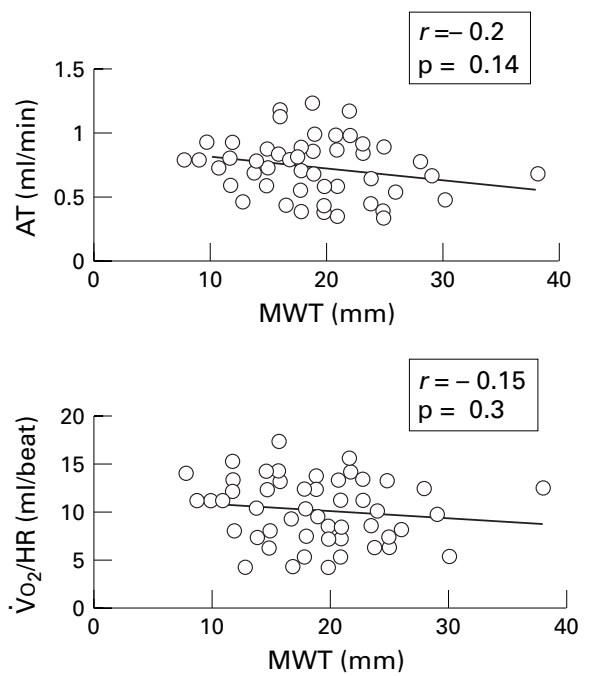

Figure 5 Oxygen uptake $\left(\dot{V}_{\mathrm{O}_{2}}\right)$, anaerobic threshold $(A T)$, ratio of change in oxygen uptake to work rate $\left(\Delta \mathrm{VO}_{2} / \Delta W R\right)$, oxygen pulse $\left(\dot{V O}_{2} / H R\right)$, and the ratio of ventilation to carbon dioxide production $\left(\dot{V}_{E} / \dot{V}_{\mathrm{CO}_{2}}\right)$ as a

function of the left ventricular maximum wall thickness
(MWT) in patients with hypertrophic cardiomyopathy.

volume during incremental exercise. We cannot rule out the possibility that this pattern of oxygen pulse may have been associated with a decreasing stroke volume and further widening of the arterial-mixed venous oxygen content difference. Patients with hypertrophic cardiomyopathy have various potential causes for reduced stroke volume response including diastolic dysfunction, ${ }^{18}$ myocardial ischaemia, ${ }^{192021}$ and left ventricular outflow obstruction. ${ }^{22}$ However, it remains difficult to assess which of these factors, if any, apply to
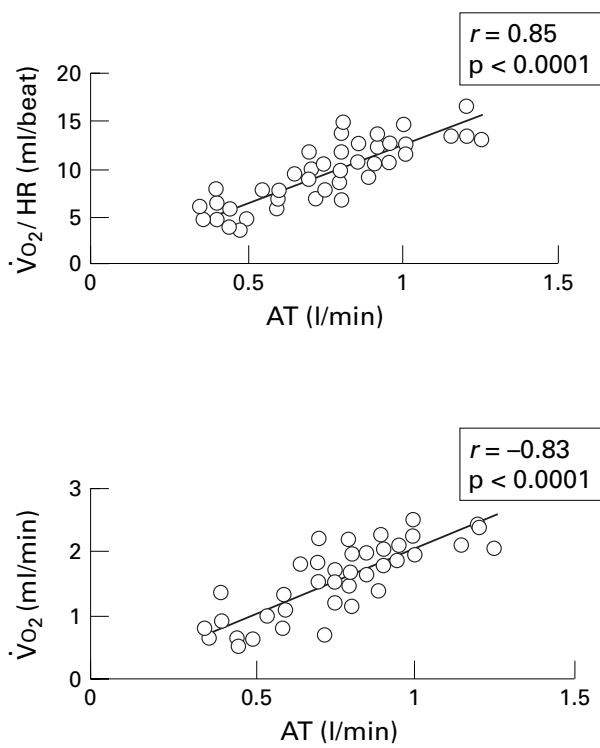

Figure 6 Oxygen uptake to work rate ratio $\left(\Delta \dot{V}_{O_{2}} / \Delta W R\right)$, oxygen pulse $\left(\dot{V}_{\mathrm{O}_{2}} / \mathrm{HR}\right)$, and oxygen uptake $\left(\dot{V}_{\mathrm{O}_{2}}\right)$, and the ratio of ventilation to carbon dioxide production $\left(\dot{V} E / \dot{V}_{\mathrm{CO}_{2}}\right)$ as a function of anaerobic threshold (AT) in patients with hypertrophic cardiomyopathy. 
individual patients. In $64 \%$ of the patients in this study the oxygen pulse did not continue to rise in the expected hyperbolic pattern and became flat. This flattening occurred at or shortly after $50 \%$ of maximum work rate. In these patients the increase in $\dot{\mathrm{V}}_{2}$ was therefore achieved by an increase in heart rate rather than by an augmentation of stroke volume or an increase in arteriovenous oxygen content difference (see fig 3 for example). A previous study showed that stroke volume was a major determinant of exercise tolerance in patients with hypertrophic cardiomyopathy. ${ }^{23}$ In that study only the peak values of stroke volume and oxygen uptake were measured. We made continuous measurements of oxygen pulse and hence were able to observe changes in temporal profile, which were not recorded in the previous study. In $28 \%$ of the patients, both the peak oxygen pulse and the peak heart rate response were reduced, although the oxygen pulse had a normal pattern. While this is consistent with the failure to augment stroke volume and to increase heart rate appropriately, it could also reflect a submaximal effort. The latter is unlikely as all these patients achieved a respiratory exchange ratio in excess of 1.2 , with end tidal $\mathrm{PCO}_{2}$ not significantly different from that in the remaining subjects. In $8 \%$ of the patients in whom the peak oxygen pulse had a hyperbolic pattern and reached a normal value, the peak heart rate response was less than $70 \%$ of the predicted value. This suggests that in these patients the "apparently normal" profile of oxygen pulse was probably the result of an inappropriate heart rate response associated with augmented stroke volume. However, the reduced heart rate response could also have increased the transit time at the periphery, resulting in further widening of the arteriovenous oxygen content difference.

ANAEROBIC THRESHOLD

In the present study, the majority of patients had a reduced anaerobic threshold. There was a significant relation between reduced anaerobic threshold and other indices of gas exchange response such as the $\dot{\mathrm{VO}}_{2}$ peak, $\dot{\mathrm{V}}_{2} / \mathrm{WR}$, $\dot{\mathrm{V}}_{2} / \mathrm{HR}$, and $\dot{\mathrm{V}} \mathrm{E} / \mathrm{CO}_{2}$. The plateau in oxygen pulse appeared at or immediately after the point where the majority of patients had reached anaerobic threshold. One explanation may be the early development of metabolic acidaemia owing to a depressed stroke volume response. Alternatively, acidaemia may have caused suppression of stroke volume ${ }^{24}$ and therefore impaired oxygen delivery.

\section{WORK EFFICIENCY}

The slope of increase in $\dot{\mathrm{V}}_{2}$ as a function of work rate $\left(\Delta \dot{\mathrm{V}}_{2} / \Delta \mathrm{WR}\right)$ - that is, the oxygen cost of the work performed-has been shown to be a major determinant of a subject's work efficiency ${ }^{1}$ or more properly its inverse. In normal individuals, this slope is approximately 10 $\mathrm{ml} / \mathrm{min} / \mathrm{W}^{25}$ In patients with heart failure, $\Delta \dot{V}_{\mathrm{O}_{2}} / \Delta \mathrm{WR}$ often becomes shallow towards the end of exercise, ${ }^{12}$ probably owing to inadequate blood supply to contracting muscles at higher work rates. While a third of patients in the present study had a $\Delta \dot{\mathrm{V}}_{2} / \Delta \mathrm{WR}$ value of less than 9 , the slope was shallow from the start of exercise in all but one. This pattern of response is described in patients with peripheral vascular disease and primary abnormalities of muscle oxygen extraction. ${ }^{1}$ It is possible that in patients with hypertrophic cardiomyopathy, as in other patients with chronic heart disease, there are skeletal muscle changes associated with reduced nutritive flow, a feature of which is poor utilisation of oxygen. As yet there is no evidence that peripheral blood flow is reduced at rest or in exercise in these patients. Changes in skeletal muscle consistent with myogenic myopathies have been reported in patients with hypertrophic cardiomyopathy. ${ }^{26}$ This raises the intriguing possibility that this pattern of $\dot{\mathrm{V}}_{2} /$ WR may be related to the expression of contractile protein gene mutation in peripheral as well as cardiac muscle in these patients. ${ }^{27} 28$

$\Delta \dot{\mathrm{V}} / \Delta \dot{\mathrm{V}} \mathrm{CO}_{2}$

In normal subjects the $\Delta \dot{\mathrm{V}} \mathrm{E} / \Delta \dot{\mathrm{V}} \mathrm{CO}_{2}$ ratio is less than 30 in the region below the anaerobic threshold. Fifty per cent of patients in our study had an abnormally high value for this slope. An increase in $\Delta \dot{\mathrm{VE}} / \Delta \dot{\mathrm{V}}_{\mathrm{CO}_{2}}$ may be the result of hyperventilation or increased dead space. In hyperventilation the arterial partial pressure of carbon dioxide is reduced as the gas is washed out. Although we did not measure the arterial $\mathrm{PCO}_{2}$ values in this study, the end tidal $\mathrm{PCO}_{2}$ response in our patient population was not significantly different from that in the controls, which suggests that the mechanism for the increased $\Delta \dot{\mathrm{V}} \mathrm{E} / \Delta \dot{\mathrm{V}} \mathrm{CO}_{2}$ ratio was increased dead space. Several studies indicate that patients with congestive heart failure have an increased $\Delta \dot{\mathrm{V}} \mathrm{E} / \Delta \dot{\mathrm{V}}_{\mathrm{CO}_{2}},{ }^{29-31}$ which is not associated with reduced arterial $\mathrm{PCO}_{2} \cdot{ }^{31}$ Increased dead space ${ }^{32}$ and ventilation/perfusion mismatch $^{33}$ were thought to be the reasons for increased $\Delta \dot{\mathrm{V}} \mathrm{E} / \Delta \dot{\mathrm{V}}_{\mathrm{CO}_{2}}$ in these studies. Suggested explanations include reduced cardiac output and microvascular dysfunction in the pulmonary vascular bed. ${ }^{34}$ The mechanism in patients with hypertrophic cardiomyopathy requires further study.

\section{CONCLUSIONS}

Our study shows that patients with hypertrophic cardiomyopathy have abnormal peak and submaximal exercise responses during incremental upright exercise. The pattern of abnormalities observed suggests that exercise limitation is caused by various different mechanisms including reduced stroke volume reserve, ventilation/perfusion mismatch, and possibly abnormal peripheral oxygen utilisation. The relation of these abnormalities to the clinical phenotype requires further study.

\footnotetext{
1 Wasserman K, Hansen J E, Sue DY, et al. Principles of exercise testing and interpretation. London: Lea and Febiger, 1994:80-94, 255-75.

2 Redwood DR, Goldstein RE, Hirshfeld J, et al. Exercise performance after septal myotomy and myectomy in patients with obstructive hypertrophic cardiomyopathy. $\mathrm{Am} \mathcal{F}$ with obstructive hypertro
Cardiol 1979;44:215-20.

3 Sue DY. Integrative cardiopulmonary testing: basis and application. Medicine, Exercise, Nutrition and Health 1994;3: 32-5.
} 
4 WHO/ISFC task force. Report of the WHO/ISFC task force on the definition and classification of cardiomyopathies. $B$ on the definition and cl
Heart $\mathcal{f} 1980 ; 44: 672-3$.

5 McKenna WJ, Castro Beiras A, Penas Lado M. The cardiomyopathies. Br Heart f 1994; 72(suppl):S4-23.

6 Russell JC, Dale JD. Dynamic torquemeter calibration of bicycle ergometers. F Appl Physiol 1086;61:1217-20.

7 Whipp BJ, Davis JA, Torres F, et al. A test to determine parameters of aerobic function during exercise. $\mathcal{F} A p p$ Physiol: Resp Environ Exerc Physiol 1981;50:217-21.

8 Porszasz J, Barstow TJ, Wasserman K. Evaluation of a symmetrically disposed Pitot tube flow meter for measuring gas flow during exercise. F Appl Physiol 1994;77:2659-65.

9 Beaver WL, Wasserman K, Whipp BJ. A new method for detecting anaerobic threshold by gas exchange. F Appl Physiol 1986;60:2020-7.

10 Sue DY, Wasserman K, Moricca RB, et al. Metabolic acidosis during exercise in patients with chronic obstructive pulmonary disease. Chest 1988;94:931-8.

11 Whipp BJ, Davis JA, Wasserman K. Ventilatory control of the "isocapnic buffering" region in rapidly-incremental the "isocapnic buffering" region in
exercise. Resp Physiol 1989;76:357-68.

12 Cohen-Solal A. Cardiopulmonary exercise testing in chronic heart failure. In: Wasserman K, ed. Exercise ga exchange in heart disease. Armonk, NY: Futura Publishing Co, 1996:17-35.

13 Whipp BJ. The bioenergetic and gas-exchange basis of exercise testing. Clin Chest Med 1994;15:173-92.

14 Bhambhani Y, Norris S, Bell G. Prediction of stroke volume from oxygen pulse measurements in untrained and trained men. Can 7 Appl Physiol 1994;19:49-59.

15 Bhambhani YN. Prediction of stroke volume during upper and lower-body exercise in men and women. Arch Phys Med Rehabil 1995;76:713-18.

16 Stratton JR, Levy WC, Cerqueira MD, et al. Cardiovascular responses to exercise. Effects of aging and exercise training in healthy men. Circulation 1994;89:1648-55.

17 Spina RJ, Ogawa T, Martin WH, et al. Exercise training prevents decline in stroke volume during exercise in young vents decline in stroke volume during exercise
healthy subjects. $\mathcal{F}$ Appl Physiol 1992;72:2458-62.

18 Maron BJ, Spirito P, Green KJ, et al. Noninvasive assessment of left ventricular diastolic function by pulsed Doppler echocardiography in patients with hypertrophic cardiomyopathy. $\mathcal{F}$ Am Coll Cardiol 1987;10:733-42.

19 Elliott PM, Rosano G, Gill JS, et al. Changes in coronary sinus $\mathrm{pH}$ during dipyridamole stress in patients with hypertrophic cardiomyopathy. Heart 1996;75:179-83.

20 Camici P, Chiriatti G, Lorenzoni R, et al. Coronary vasodilatation is impaired in both hypertrophied and nonhypertrophied myocardium of patients with hypertrophic cardiomyopathy. Circulation 1993;87:1580-90.
21 Panza JA, Maris TJ, Maron BJ. Development and determinants of dynamic obstruction to left ventricular outflow in young patients with hypertrophic cardiomyopathy. Circulation 1992;85:1398-405.

22 Chikamori T, Dickie S, Poloniecki JD, et al. Prognostic significance of radionuclide-assessed diastolic dysfunction in hypertrophic cardiomyopathy. Am f Cardiol 1990;65:47882 .

23 Lele SS, Thomson HL, Seo H, et al. Exercise capacity in hypertrophic cardiomyopathy. Role of stroke volume limitation, heart rate, and diastolic filling characteristics. Circulation 1995;92:2886-94.

24 Winter UJ, Gitt AK, Fritsch J, et al. Cardiopulmonary capacity in patients with coronary heart disease. $Z$ Kardiol 1994;83 (suppl 3):73-82.

25 Hansen JE, Casaburi R, Cooper DM, et al. Oxygen uptake as related to work rate increment during cycle ergometer exercise. Eur f App Physiol 1988;57:140-5.

26 Caforio AL, Rossi B, Risaliti R, et al. Type 1 fiber abnormalities in skeletal muscle of patients with hypertrophic and dilated cardiomyopathy: evidence of subclinical trophic and dilated cardiomyopathy: evidence of subclinical myogenic myopathy

27 Thierfelder L, Watkins H, Macrae C, et al. Alphatropomyosin and cardiac troponin $\mathrm{t}$ mutations cause familal hypertrophic cardiomyopathy: a disease of the sarcomere. Cell 1994;77:701-12.

28 Lankford EB, Fananapazir L, Sweeney HL. Abnormal contractile properties of muscle fibres expressing beta-myosin heavy chain gene mutations in patients with hypertrophic cardiomyopathy. F Clin Invest 1995;95:1409-12.

29 Banning AP, Lewis NP, Northridge DB, et al. Perfusion ventilation mismatch during exercise in chronic heart failure-an investigation of circulatory determinants. $\mathrm{Br}$ Heart f 1995;74:27-33.

30 Chua TP, Coats AJ. The lungs in chronic heart failure. Eur Heart f 1995;16:882-7.

31 Al-Rawas OA, Carter R, Richens D, et al. Ventilatory and gas exchange abnormalities on exercise in chronic heart failure. Eur Respir f 1995;8:2022-8.

32 Clark AL, Chua TP, Coats AJ. Anatomical dead space, ventilatory pattern, and exercise capacity in chronic heart failtilatory pattern, and exercise capacit
ure. Br Heart $\mathcal{F} 1995 ; 74: 377-80$.

33 Clark AL, Volterrani M, Swan JW, et al. Ventilationperfusion mismatch in chronic heart failure. Int $\mathcal{F}$ Cardiol 1995;48:259-70.

34 Clark AL, Volterrani M, Swan JW, et al. The increased ventilatory response to exercise in chronic heart failure: relation to pulmonary pathology. Heart 1997;77:138-46. 